http://dx.doi.org/10.1016/j.aller. 2012.03.001

2. Park HS, Choi GS, Cho JS et al. Epidemiology and current status of allergic rhinitis, asthma, and associated allergic diseases in Korea: ARIA Asia-Pacific workshop report. Asian Pac J Allergy Immunol 2009;27(2-3):167-71.

3. Bunnag C, Jareoncharsri P, Tantilipikorn P et al. Epidemiology and current status of allergic rhinitis and asthma in Thailand -- ARIA Asia-Pacific Workshop report. Asian Pac J Allergy Immunol 2009;27(1):79-86

4. Global Initiative for Asthma (GINA). Global Strategy for Asthma Management and Prevention. GINA, 2011. Available from: www.ginasthma.org

5. Zhao J, He Q, Zhang G et al. Status of asthma control in children and the effect of parents' knowledge, attitude, and practice (KAP) in China: a multicenter study. Ann Allergy Asthma Immunol 2012;109(3):190-4. http://dx.doi.org/10.1016/j.anai.2012.07.005.

6. Chan PW, DeBruyne JA. Parental concern towards the use of inhaled therapy in children with chronic asthma. Pediatr Int 2000;42(5):547-51. http://dx.doi.org/10.1046/j.1442-200x.2000.01278.x

7. Brand $\mathrm{PL}$, Baraldi $\mathrm{E}$, Bisgaard $\mathrm{H}$ et al. Definition, assessment and treatment of wheezing disorders in preschool children: an evidence-based approach [European Respiratory Society Taskforce]. Eur Resp J 2008;32:1096-110. http://dx.doi.org/10.1183/09031936.00002108

8. Wong GW, Kwon N, Hong JG et al. Pediatric asthma control in Asia: Phase 2 of the Asthma Insights and Reality in Asia-Pacific (AIRIAP 2) survey. Allergy 2013;68(4):524-30. http://dx.doi.org/10.1111/all.12117.
9. Sleath B, Ayala GX, Gillette $C$ et al. Provider demonstration and assessment of child device technique during pediatric asthma visits. Pediatrics 2011;127: 6428. http://dx.doi.org/10.1542/peds.2010-1206

10. Ait-Khaled N, Enarson DA, Bissell $\mathrm{K}$ et al. Access to inhaled corticosteroids is key to improving quality of care for asthma in developing countries. Allergy 2007;62(3):230-6. http://dx.doi.org/10.1111/j.1398-9995.2007.01326.x

11. Aït-Khaled N, Auregan G, Bencharif $N$ et al. Affordability of inhaled corticosteroids as a potential barrier to treatment of asthma in some developing countries. Int J Tuberc Lung Dis 2000;4(3):268-71.

12. Slader $C A$, Reddel HK, Jenkins $C R$ et al. Complementary and alternative medicine use in asthma: who is using what? Respirology 2006;11:373-87. http://dx.doi.org/10.1111/j.1440-1843.2006.00861.x

13. Prabhakaran L, Lim G, Abisheganaden J et al. Impact of an asthma education programme on patients' knowledge, inhaler technique and compliance to treatment. Singapore Med J 2006;47(3):225-31.

14. Wang KY, Chian CF, Lai HR et al. Clinical pharmacist counseling improves outcomes for Taiwanese asthma patients. Pharm World Sci 2010;32(6):721-9. http://dx.doi.org/10.1007/s11096-010-9427-4

15. Yeh KW, Chen SH, Chiang LC et al. Survey of asthma care in Taiwan: a comparison of asthma specialists and general practitioners. Ann Allergy Asthma Immunol 2006;96(4):593-9.

http://dx.doi.org/10.1016/\$1081-1206(10)63555-7

\title{
Everyday clinical practice and its relationship to 2010 and 2011 GOLD guideline recommendations for the management of COPD
}

\author{
*Maria Papala1', Nora Kerenidi', Konstantinos I Gourgoulianis ${ }^{2}$ \\ 1 Respiratory Clinic, University hospital of Larissa, University of Thessaly, Greece \\ 2 Professor, Respiratory Clinic, University hospital of Larissa, University of Thessaly, Greece
}

*Correspondence: Maria Papala, Farmakidou 16, Larissa, 41222, Greece Tel: 00302410530604 Fax: 00302410537333

E-mail: mariapapala@hotmail.com

Received 3rd July 2013; accepted 5th July 2013; online 29th August 2013 (c) 2013 Primary Care Respiratory Society UK. All rights reserved

http://dx.doi.org/10.4104/pcrj.2013.00073

\section{Dear Sirs,}

Chronic obstructive pulmonary disease (COPD) represents a leading cause of morbidity and mortality in ageing populations. ${ }^{1}$ However, there is a significant dissociation between guideline recommendations for managing COPD and clinicians' practice. Several studies have suggested that adoption of the GOLD guidelines has been suboptimal. For the first time, the revised GOLD Guidelines published in $2011^{2}$ suggest a combined assessment of symptoms, the degree of airflow limitation as measured by spirometry, and the risk of future exacerbation, with patients grouped into four different classes in order to guide therapy.

We therefore conducted a study to compare the regular pharmacological treatment of stable COPD patients in clinical practice with the previous (2010) and current (2011) GOLD guidelines and to investigate whether the new classification of patients improved adherence to GOLD recommendations.

A cohort of 127 consecutively selected patients with stable
COPD (122 male, mean age $69.6 \pm 8.8 y e a r s$ (range: 47-83)) were enrolled in the study. COPD diagnosis was based on global assessment including clinical history and an obstructive spirometry pattern (post-bronchodilator $\mathrm{FEV}_{1} / \mathrm{FVC}$ ratio $<0.70$ ). Initially, the appropriateness and inappropriateness (under- or over-prescription) of pharmacotherapy was established in accordance with the previous GOLD guidelines. ${ }^{3}$ Afterwards, the study population's treatment was reassessed based on current GOLD recommendations. ${ }^{2}$ Individuals with a history of upper or lower respiratory tract infection during the previous four weeks, co-existing asthma, cancer or serious uncontrolled disease were excluded from the study. The protocol was approved by the local ethics committee of the University Hospital of Thessaly and all patients provided written informed consent.

A total of 117 patients $(92.1 \%$ ) received bronchodilators. Longacting antimuscarinic agents (LAMAs) were the most prescribed drugs, being included in the standard therapy of 98 patients (77.1\%), and used as monotherapy in 15 patients (11.8\%). Longacting $\beta_{2}$-agonists (LABAs) were prescribed in 86 patients $(67.7 \%)$. Triple therapy (LAMA, LABA and inhaled corticosteroid (ICS)) was used in 57 patients (44.8\%) at all stages of the disease.

The patterns (correct, under- and over-treatment) of COPD patients' treatment in daily practice according to the GOLD 2010 and 2011 recommendations are shown in Table 1. COPD patients with early disease presented higher rates of over-treatment compared to patients with advanced disease according to both 
Table 1. Pattern of correct, under- and over-treatment by patient group according to GOLD 2010 and GOLD 2011 recommendations

$\begin{array}{lllll}\begin{array}{l}\text { Correct } \\ \mathrm{N}(\%)\end{array} & \begin{array}{l}\text { Under-treatment } \\ \mathrm{N}(\%)\end{array} & \begin{array}{l}\text { Over-treatment } \\ \mathrm{N}(\%)\end{array} & \begin{array}{l}\mathrm{p} \\ \text { (between stages) }\end{array} & \begin{array}{l}\mathrm{p} \\ \text { (expected } \\ \end{array} \\ & & & \begin{array}{l}\text { according to } \\ \text { guidelines- } \\ \text { actually observed) }\end{array} \\ \end{array}$

\section{GOLD 2010 recommendations}

\begin{tabular}{|c|c|c|c|c|c|}
\hline All patients, $N=127$ & $52(40.9)$ & $3(2.4)$ & $72(57.5)$ & & \\
\hline Stage I, $\quad N=10$ & $3(30.0)$ & 0 & $7(70.0)$ & \multirow{4}{*}{0.921} & 0.011 \\
\hline Stage II, N=50 & $20(40.0)$ & 0 & $30(60.0)$ & & $<0.001$ \\
\hline Stage III, N=48 & $18(37.5)$ & $2(4.1)$ & $28(58.4)$ & & $<0.001$ \\
\hline Stage IV, $N=19$ & $11(57.9)$ & $1(5.3)$ & $7(36.8)$ & & $<0.001$ \\
\hline
\end{tabular}

\begin{tabular}{|c|c|c|c|c|c|}
\hline \multicolumn{6}{|c|}{ GOLD 2011 recommendations } \\
\hline All patients, $\mathrm{N}=127$ & $89(70.1)$ & $4(3.1)$ & $36(28.3)$ & & \\
\hline Group A, N=30 & $13(43.3)$ & $1(3.3)$ & $17(56.7)$ & 0.048 & 0.016 \\
\hline Group C, N=34 & $21(61.7)$ & $1(2.9)$ & $13(10.2)$ & & $<0.001$ \\
\hline Group D, N=54 & $52(96.2)$ & $1(1.8)$ & 0 & & 0.001 \\
\hline
\end{tabular}

versions of the guidelines. Observed adherence to treatment differed from expected in all stages and groups, whereas the differences between groups were marginally statistically significant ( $p=0.048$ ) only in the case of the 2011 guidelines (Group B differed from the others, exhibiting the lowest adherence percentage of $33 \%)$, while no differences between stages were observed in the case of the 2010 guidelines $(p=0.0921)$. However, the combined assessment seemed to benefit more high risk patients, as the percentage dropped to $10.2 \%$ and $0 \%$ in Groups C and D respectively.

The results of our study show that the rate of adherence to the GOLD guideline has increased from $40.9 \%$ with the 2010 version to $70.1 \%$ with the 2011 version. Nevertheless, over-treatment remains high in low risk COPD patients.

There are several reasons which might explain the improved adherence to the latest 2011 recommendations. The new categories have led to patients being categorised as having 'worse' COPD; consequently, combined medical treatment including ICS as well as LAMAs and LABAs which would have been regarded as overtreatment according to the 2010 guideline is now considered correct according to the 2011 guideline. Moreover, the new guideline includes a wider choice of second choice respiratory medications, so patients previously considered to be over-treated are now treated appropriately; $96.2 \%$ of patients in Group D (2011 guidelines) are being treated appropriately as opposed to $57.9 \%$ in Stage IV ( 2010 guidelines).

Compliance with the new 2011 guideline is low, despite the appropriate classification of patients and the strategy of early implementation of COPD guidelines. This is not a domestic phenomenon. Recent international research reveals discrepancies between expected and observed treatment regimes: Asche et al. found that $66 \%$ of their study population were prescribed medications inconsistent with their spirometry results, ${ }^{4}$ while other researchers suggest less than optimal adherence with recommended drug therapy treatment for COPD patients based on GOLD guidelines. ${ }^{5-7}$

The appropriate use of COPD medications is both cost effective and clinically beneficial for patients and stakeholders. Nevertheless, physicians' knowledge and use of guidelines seems to be insufficient, with deficits in the pharmacological treatment of COPD. Changes in health care systems must include more effective ways to transfer knowledge into clinical practice. High quality education may raise the standards of health care provided for patients with COPD. However, as real life often demands an individualised treatment approach, the contribution of other factors to COPD treatment (comorbidities, access to health care facilities, patient educational level) also needs to be investigated in the future.

\section{Handling editor Paul Stephenson}

Conflicts of interest The authors declare that they have no conflicts of interest in relation to this article.

Contributorship All authors participated in study design. Gourgoulianis Kl: Critically reviewed the paper. Kerenidi N: Writing, Data collection. Papala M: Writing, data collection, statistics.

\section{Funding None.}

\section{References}

1. Minas M, Kostikas K, Papaioannou Al. The association of metabolic syndrome with adipose tissue hormones and insulin resistance in patients with COPD without co-morbidities. COPD 2011;8(6):414-20. http://dx.doi.org/10.3109/15412555.2011.619600

2. Global Initiative for Chronic Obstructive Lung Disease (GOLD). Global strategy for the diagnosis, management, and prevention of Chronic Obstructive Lung Disease (revised 2011), www.goldcopd.com. 
3. Global Initiative for Chronic Obstructive Lung Disease (GOLD). Global strategy for the diagnosis, management, and prevention of Chronic Obstructive Lung Disease (updated 2010), www.goldcopd.com.

4. Asche CV, Leader S, Plauschinat C, et al. Adherence to current guidelines for chronic obstructive pulmonary disease (COPD) among patients treated with combination of long-acting bronchodilators or inhaled corticosteroids. Int J Chron Obstruct Pulmon Dis 2012;7:201-09.

http://dx.doi.org/10.2147/COPD.S25805

5. Franssen FM, Spruit MA, Wouters EF. Determinants of polypharmacy and compliance with GOLD guidelines in patients with chronic obstructive pulmonary disease. Int J Chron Obstruct Pulmon Dis 2011;6:493-501. http://dx.doi.org/10.2147/COPD.S24443

6. Fitch K, Iwasaki K, Pyenson B, Plauschinat C, Zhang J. Variation in adherence with Global Initiative for Chronic Obstructive Lung Disease (GOLD) drug therapy guidelines: a retrospective actuarial claims data analysis. Curr Med Res Opin 2011;27(7):1425-9. http://dx.doi.org/10.1185/03007995.2011.583230

7. Lucas AE, Smeenk FW, Smeele IJ, van Schayck CP.Overtreatment with inhaled corticosteroids and diagnostic problems in primary care patients: an exploratory study. Fam Pract 2008;25(2):86-91. http://dx.doi.org/10.1093/fampra/cmn006

\section{Available online at http://www.thepcrj.org}

